\title{
ROTARY INDEX TABLE USED ON MULTI-AXIS MACHINING CENTERS
}

\author{
FUNARU, M[arian]; MIHAILA, L[ucian]; PASCU, M[arius] \& ANDRIOAIA, D[ragos]
}

\begin{abstract}
Growing performance demands in the mechanical manufacturing field have lead to a great development of the machine tools domain, during the past decades, regarding especially the productivity and the manufacturing precision. When equipping a machine tool with an automatic tool changer and an automatic pallet mechanism, the obtained result is a machining center. For single or small series products, multiaxis machining centers fulfill the precision and productivity requirements, through the advantages of a reduced auxiliary time and reduced operating errors.

This paper presents a new technical solution of the index table mechanism used on multi-axis machining centers, which significantly helps reduce the auxiliary time in the manufacturing process.

The mechanical structure of the table mechanism described in this paper offers the possibility to obtain a very high positioning precision, using a curvic coupling and a hidraulically driven table clamp/unclamp mechanism.

Keywords: machining center, index table, clamp/unclamp mechanism, positioning precision
\end{abstract}

\section{INTRODUCTION}

Recent developments in the machine tools domain are determined by the necessity for new and improved constructive solutions, in order to solve the inherent conflict between the precision and the productivity of the machine tools [1][2][3].

The trends of performance requirements for mechanical manufacturing are characterised by the constantly growing demands for the machine tools positioning precision, the challenge also consisting in the ability to produce mechanical pieces with very high precision and also at reasonable production costs [2].

In order to meet these ambitious demands, it is necessary to find solutions regarding the shortening of the process time, which can be accomplished by increasing the productivity of the manufacturing process, since increasing the precision of the procedures is in many cases limited by the physical principles which underly these procedures and by the performances of the mechanical part of the machine tool [3].

Regarding the shortening of the auxiliary times which leads to a reduced manufacturing time, the machine tools equipped with numerical controls are provided with pallet mechanisms and automatic tool changers, thus obtaining a machining center [4].

The machining centers present the advantage of an increased productivity, due to the reduced auxiliary time, through concentrating a higher number of operations needed for changing the workpiece and avoiding the removal, transport, setting and alignment of the workpiece, which in many cases represents the source of many errors. In the case of machining centers, the chip to chip tool changing time can be shortened to even approximately two seconds and the pallet changing time to even seven seconds [5].

Another main advantage is represented by the increased machining accuracy, achieved through eliminating the errors caused by setting the workpiece on the machine tool table, by a human operator. These advantages are made obvious when having to produce single or small series workpieces, which require several and complex operations. In this context, an important role in accomplishing a high positioning precision and productivity is held by the machine tool table as part of the machining center [4].

In the past decades, the demand of productivity and accuracy of workpieces is being fulfilled by multi-axis machining centers, the workpiece accuracy mainly depending on the motion accuracy of the parts used to assemble the machine tools [6].

Multi-axis machining centers consist of linear and rotary feed axes. Regarding the rotary axis, there are a number of features such as backlash, rotational fluctuation, stiffness etc. that affect the positioning precision [6].

Several types of table rotation mechanisms have been introduced by machine tools manufacturers, the rotary axes still finding themselves in the development phase. Conventional worm and geer mechanisms are considered to be the most common solution to the drive requirements on most rotary tables currently in manufacture today, providing a good positioning precision. However, when driven against a load, the accuracy generally deteriorates due to the mechanical wear characteristics of the gear system [7].

To improve the wear characteristics, the spiral worm gear was developed. This solution provides an up to six times more gear contact than the conventional system, having a good positioning precision and repeatability [7].

A new research direction is made towards the use of a roller drive mechanism in the configuration of the rotary table, which consists of a globoidal cam and a roller gear, the experimental results revealing higher performances in comparison with the conventional worm gear 
mechanism, used with prevalence by the machine tools constructors [6].

In order to increase the accuracy and repeatability of the rotary axis, a recirculating ball drive rotary table was also designed, based on the advantages of the ballscrew, emphasized by the linear axes: fast, rigid and highly precise positioning, long operating lifetime, without the need for maintenance [8].

Another recent trend in the rotary table field is represented by the direct drive rotary table, which eliminates the undesired phenomena caused by the mechanichal gearing system or by the ballscrew transmission; the rotary table is driven directly by the electromagnetic force of the motor [7].

The subject of this paper is a techical solution of an index table mechanism used on multi-axis machining centers, which represents a critical element in the rotary axis structure, with a direct effect on the manufacturing precision. The solution presented in this paper uses a high precision curvic coupling, with a $1^{\circ}$ minimum indexing angle, and a hidraulically driven table clamp/unclamp mechanism.

\section{STRUCTURE OF THE TABLE ROTATION MECHANISM}

The table rotation mechanism has the main purpose of ensuring the relative angular position of the workpiece set on the machine tool table surface, against the cutting tool tip. The manufacturing precision of the machining center is directly affected by the positioning precision of the rotary axis, given by the indexing mechanism.

As regard to its structure, the table rotation mechanism comprises several main components, beginning with the servomotor 2, having an attached pulse coder, which monitors the position and speed of the machine tool table. The servomotor transmits the rotation motion over to the curvic coupling 5 , through the gearing system, which is composed of gear 1 , engaged with gear 3 and the pinion shaft 4 .

The curvic coupling 5 has a precision external toothing, which allows it to interlock with the pinion shaft and rotate the machine tool table. The upper part of the curvic coupling is connected to the positioning base 6 , and the bottom part is connected to the machine tool frame. The curvic coupling used in this technical solution meets the need for the highest accuracy at maximum load capacity, after the pallet and workpiece were set and locked on the machine tool table. The curvic design of the coupling has the major advantage of ensuring a precise, low weight and compact connection, in which the curvic toothing shape facilitates the self-centering of the coupling, thus increasing the indexing precision of the machine tool table, under high loadings.

The positioning base is provided with four locating cones 7 , which are used for pallet clamping, using the same hydraulic unit as the index table mechanism.
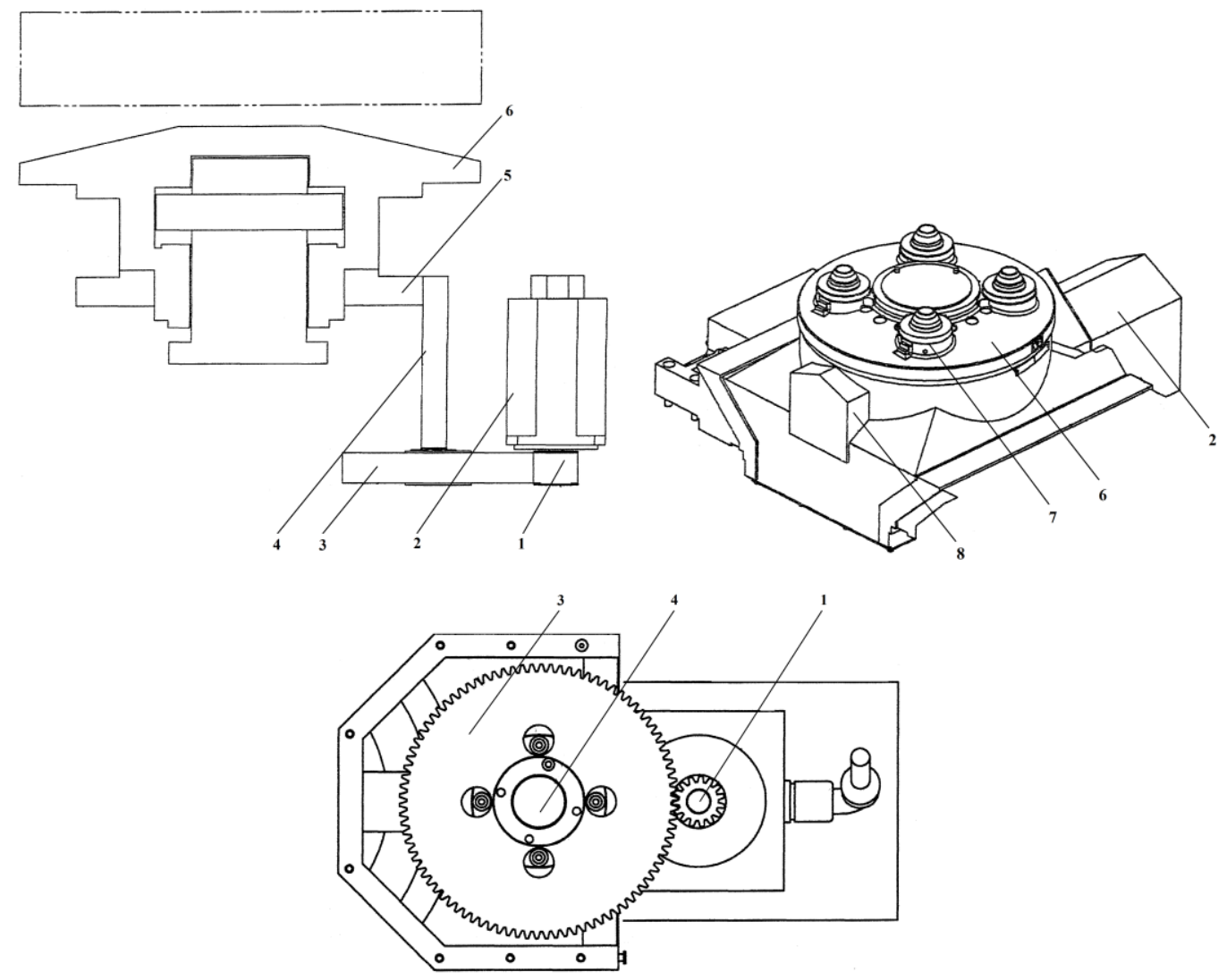

Fig. 1. General structure of the table rotation mechanism 


\section{INDEX TABLE FUNCTIONING}

This technical solution regarding the index table mechanism and the table clamp and unclamp mechanism, provides a high positioning precision and repeatability, together with a high rigidity, the secure locking of the positioning base of the machine tool table being achieved through hydraulic pressure.

Mainly, the operating sequences for indexing and clamping/umclamping the rotary table are the following: first, the table unclamping command is given, the positioning base moves upward, driven by a double piston and the curvic couplings are being disengaged; then the servomotor transmits the rotation motion through the gearing system, to the curvic coupling, which rotates the positioning base, with a minimum one angle degree. Finally, after indexing the positioning base in the desired position, the table clamp command is given, the positioning base is being moved downward also by hydraulic pressure and the curvic couplings are being engaged. During table rotation, the position and speed of the table are monitored by a pulse coder attaced to the servomotor, which closes the closed-loop control system.

\subsection{Table clamp}

During the manufacturing process, the rotary table needs to execute angular positioning displacements in order to provide the required position of the workpiece, relative to the cutting tool tip. In fig. 2 it is represented the table clamp mechanism, which secures (clamps) and releases (unclamps) the positioning base 2 . The table clamping and unclamping are performed by hidraulic pressure, provided by the machine hydraulic unit 8 , the same used for the pallet clamp and unclamp operations. The completion of these operations are confirmed by two pressure switches 8 (fig. 1), which send appropriate signals to the machine tool controller.

When the table clamping is commanded, the solenoid valve 5 (table unclamp) is de-energized and the solenoid valve 6 (table clamp) is energized, changing its position from 0 to 1 . The hydraulic oil supplied by the hydraulic unit 8 enters area " $A$ " of the cylinder 4 , which causes the positioning base 2 to move downward by hidraulic pressure and curvic coupling 3 also moves downward. The curvic couplings 3 and 9 are engaged and the proximity switch detects the table clamp, sending the signal to the machine controller, which confirms the completion of table clamping. The check valve 7 has the purpose of maintaining an adequate pressure level in case of machine tool power failure, preventing the oil from leaking back to the hydraulic unit and accidentally unclamping the table.

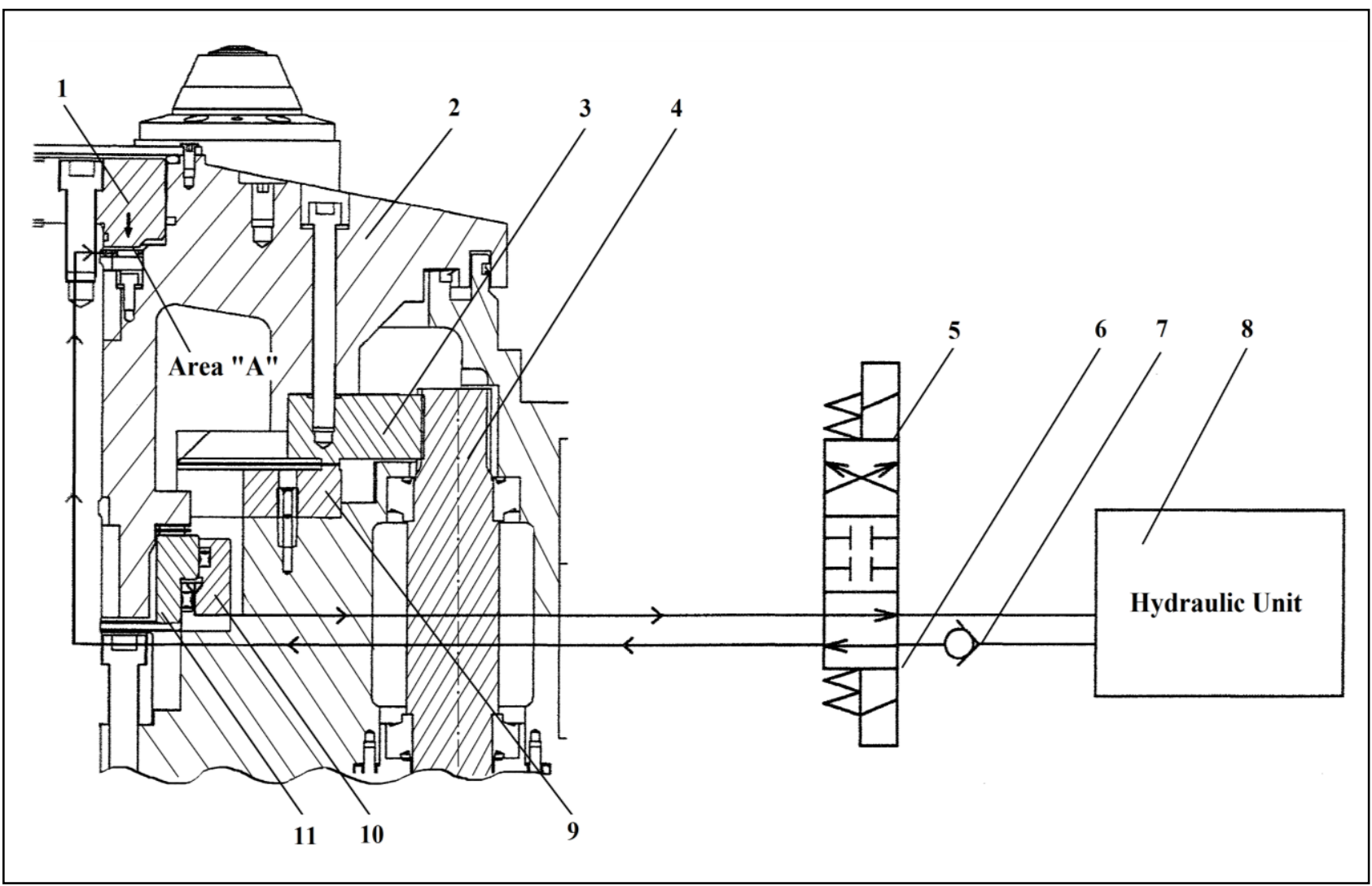

Fig. 2. Table clamp mechanism

\subsection{Table unclamp}

Fig. 3 represents the table unclamp mechanism; when the machine controller gives the table unclamping command, the solenoid valve 6 is de-energized, changing its position from 1 to 0 and the solenoid valve 5, responsible for table unclamping is energized and changes its position form 0 to 1 . The hydraulic oil driven from the hydraulic unit 8 enters area "B", determining the positioning base 2 to move upward and the curvic coupling 3 also moves upward. As a result, the curvic couplings 3 and 9 disengage, the proximity switch detects the table unclamp and sends a signal to the 
machine controller, which confirms the completion of table unclamping and gives the rotation command to the servomotor, to index the machine tool table in the required position, by rotating the pinion shaft 4 .
The check valve 7 keeps the pressure level in area B and prevents the hydraulic oil from leaking back to the hydraulic unit in case of power failure and cause damage by accidentally moving down the positioning base during the indexing operation.

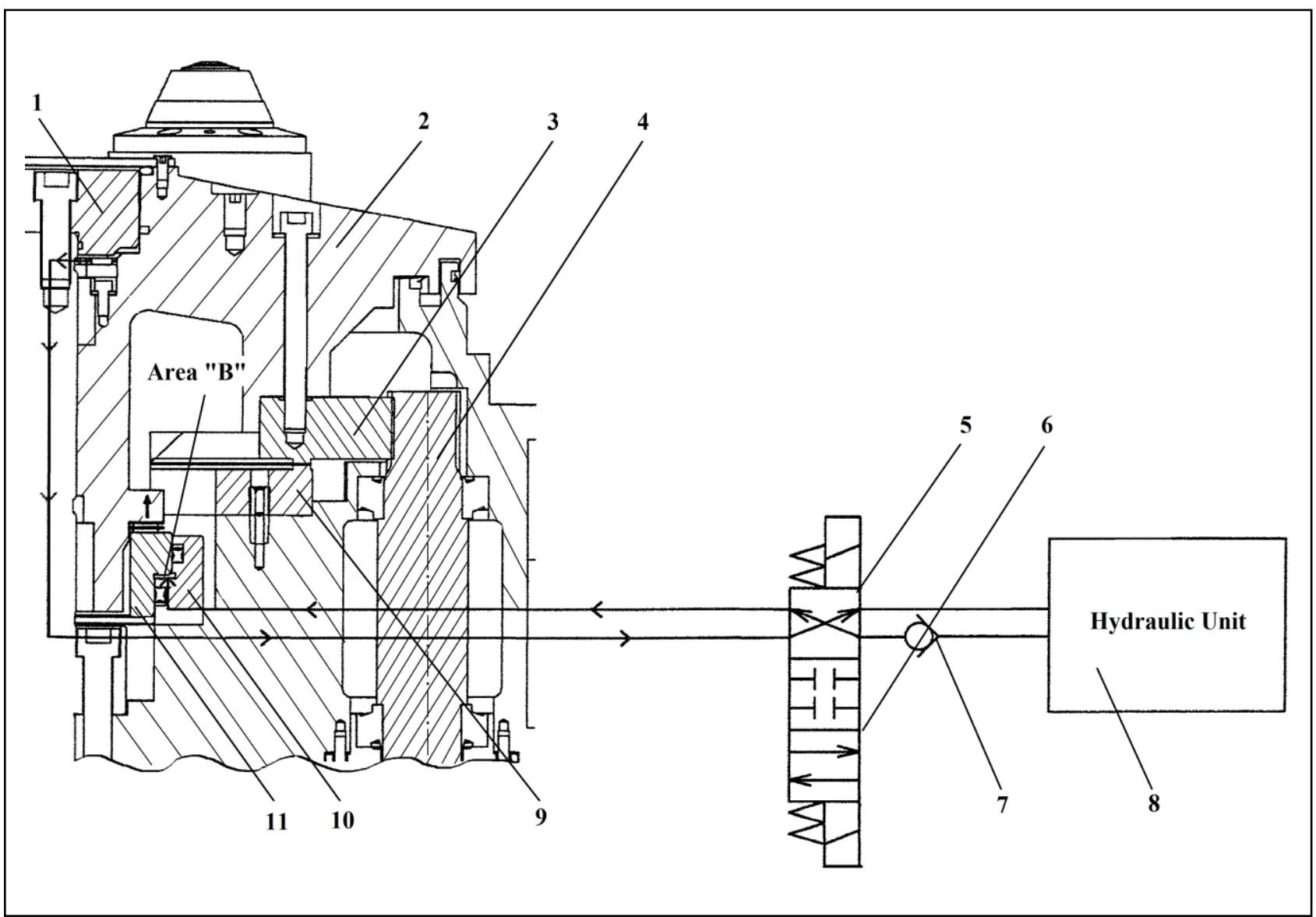

Fig. 3. Table unclamp mechanism

\section{CONCLUSIONS}

Equipping the numerically controlled machine tools with automatic tool changers and automatic pallet changers has lead to the development of multi-axis machining centers, which include linear and rotary feed axes in their structure.

The index table mechanism, together with the table clamp/unclamp mechanism presented in this paper, play an important role in the efficiency of a multi-axis machining center.

The index table rotation mechanism offers a high positioning precision and also a high repeatability, by making use of a precise curvic coupling in the mechanism structure, which has a minimum indexing angle of one degree. The gears and pinion shaft used in the transmission system are manufactured in a high accuracy class.

The main advantage of the presented technical solution is that it reduces the non cutting time from the manufacturing process, thus leading to a high productivity. Together with the automatic pallet changer, this solution significantly reduces the auxiliary time and also the errors caused by setting the workpiece on the machine tool table.
The table clamp/unclamp mechanism is hydraulically driven, ensuring a fast and accurate table position. The hydraulic unit used for the table clamping and unclamping operations is the same used for securing and releasing the pallet on the machine tool table, leading to a more compact design of the machining center.

\section{REFERENCES}

[1] European Commission, (2004). Manufuture: A Vision for 2020, Report of the High-Level Group

[2] Chryssolouris, G. (2005). Manufacturing Systems: Theory and Practice, Springer-Verlag, New York

[3] Byrne, G., Dornfeld, D., Denkena, B. (2003). Advancing Cutting Technology, CIRP Annals, 52/2:483-507

[4] Stan, Gh. (2003). Pallet mechanism used on machining centers, Bulletin of the Polytechnic Institute of Jassy, XLIX (LIII)

[5] Zetu, D., Carata, E., (1998). Flexible Manufacturing Systems (In Romanian), pp. 86,87, JUNIMEA, Jassy

[6] Muditha Dassanayake, K.M., Masaomi Tsutsumi (2009). High Performance Rotary Table for Machine Tool Applications. Development report. Sankyo Seisakusho Co., University of Agriculture and Technology, Tokyo

[7] http://www.cncrotary.com, (2010). Introduction to rotary table systems, Accessed on: 2012-04-15

http://www.detlevhofmann.de, (2010). Detlev Hofmann GmbH. Accessed on: 2012-03-28 